\title{
Staff involvement in the design of a key skills curriculum model: a case-study
}

\author{
ANTHONY KELLY, MEL WEST and LESLEY \\ DEE \\ University of Cambridge
}

\begin{abstract}
This case-study follows a school as it struggles to prepare for the changes brought about by Curriculum 2000 and the new key skills qualification. It describes the curriculum debate within the senior management team as it balanced the conflicting needs of subject popularity and necessity. It relates how inherent structural flaws were uncovered in the proposed curriculum strategy, how this very failure was used as an opportunity to initiate staff involvement in the design of curriculum structures and how success was subsequently fashioned from the process. It is a story of failure, consideration, reflection and improvement, and offers some insight into the lessons learned by management and teaching staff as they reflect on the process of change and their own participation in it.
\end{abstract}

\section{KEY WORDS}

key skills; curriculum structure; integrated delivery; staff involvement in structural change; gender imbalance.

\section{INTRODUCTION}

As schools and colleges struggle to introduce structures for delivering the new key skills qualification and Curriculum 2000, many managers are faced with staffing and resource uncertainties. Recent research (West and Dee et al., 2000) has shown that many centres have opted for modes of delivery which 
are part integrated and part discrete. They are integrated in the sense that they aspire to the organizational incorporation of key skills into vocational and academic courses; and they are discrete in that some aspects are delivered (by specialist key skills trained staff) independently of the intrinsic relationship between key skills and coursework.

This research-based article is a case-study of one centre which opted for discrete delivery of Information Technology and integrated delivery of both Application of Number and Communication. It describes how subjects were grouped for Curriculum 2000 delivery and how structures were designed to deliver key skills as part of that new curriculum. The article relates how inherent flaws were uncovered in the curriculum proposals and how the school used these difficulties to involve staff (for the first time) in the design of curriculum structures.

\section{SCENARIO}

The case-study is of a non-selective oversubscribed secondary school with in excess of one thousand pupils, almost 18 per cent of whom are in the sixth form. The school is situated in the semi-rural outskirts of a large industrial town and has no significant ethnic minority presence. The area generally is recovering from a period of devastating unemployment, but most students come from backgrounds where at least one parent is now in full-time employment. Less than 10 per cent of students are entitled to free school meals.

The school is successful academically with approximately 70 per cent achieving five A-C GCSE grades and the average A level points per student stands at well over twenty. The school does not offer GNVQ. The school is managed by a senior management team comprising the Head, two Deputies, a Finance Manager and a Head of Sixth. The Deputy Head (Curriculum) manages five Heads of Faculty and the Deputy Head (Pastoral) manages five Heads of Year.

\section{GROUPING SUBJECTS FOR CURRICULUM 2000}

Table 1 shows the range of A level subjects available in the school. There was considerable discussion within the senior management team as to how to arrange these subjects into groups for students entering Year 12, so that they could typically present five AS subjects. Essentially, the discussions appeared to centre on the tension between popularity and necessity. Heads of Faculty, represented on the senior management team by the Curriculum Deputy, argued for the inclusion of their subjects either on the basis that they were 
Table 1 Range of A level subjects

Subjects available at A/AS level

\begin{tabular}{lll}
\hline Art \& Design & Economics & German \\
Biology & English (Lang.) & History \\
Business Studies & English (Lit.) & Maths \\
Chemistry & French & PE \\
Computer Studies & General Studies & Physics \\
Design \& Technology & Geography & Spanish \\
\hline
\end{tabular}

popular with students (for whatever reason) or that students needed to have those subjects available to them for certain career choices (physics for engineering; chemistry for medicine; etc.).

Figure 1 is an attempt to represent this tension. Subjects are indexed according to their popularity, with the lowest number representing the subject most often taken at A level.

Following their deliberations, members of the senior management team decided, as far as possible, to group subjects on the basis of keeping popular subjects apart and avoiding conflicts between subjects essential for entry to certain HE courses. Table 2 shows the final groupings.

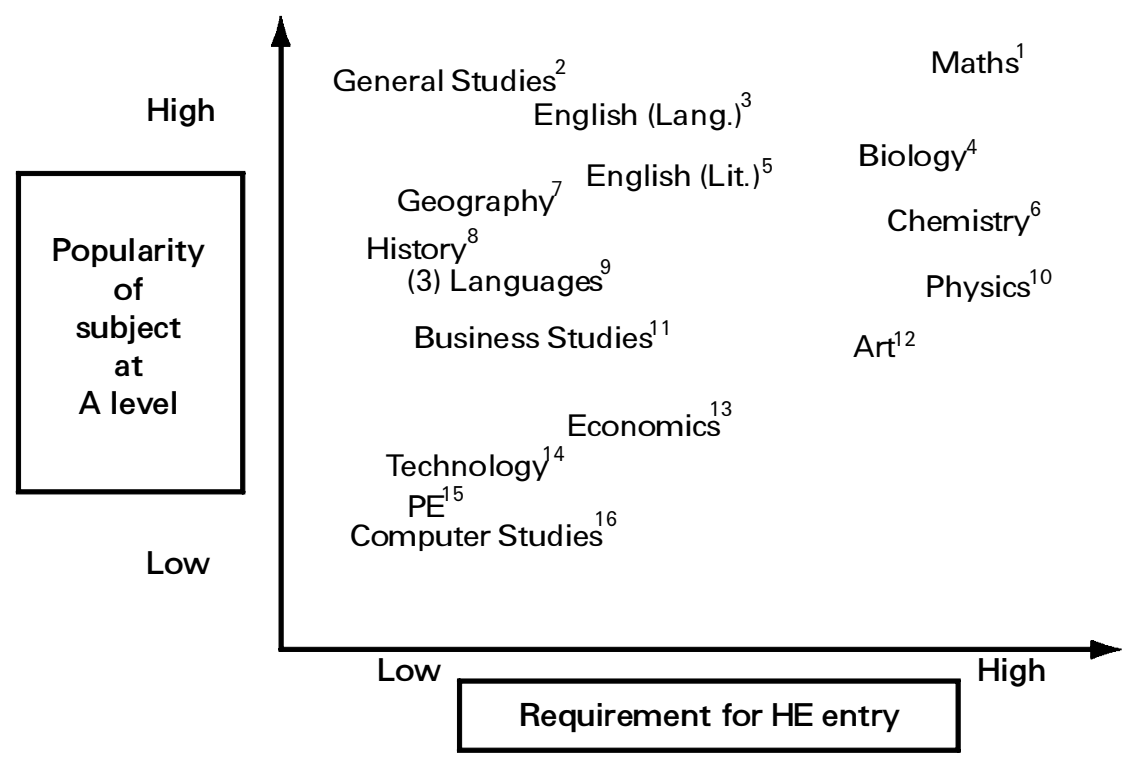

Figure 1 The popularity and necessity of subjects 
Table 2 Groupings

\begin{tabular}{llllc}
\hline Group I & Group II & Group III & Group IV & Group V \\
\hline Economics & Maths & Biology & Geography & Computer \\
Biology & Geography & English (Lit.) & Art & Studies \\
Spanish & English (Lang.) & French & Technology & \\
Maths & History & Physics & Chemistry & Tutorial \& \\
General Studies & German & Business Studies & English (Lit.) & $\begin{array}{c}\text { enrichment } \\
\end{array}$ \\
& PE & & & programmes \\
\hline
\end{tabular}

\section{SELECTING SUBJECTS FOR KEY SKILLS DELIVERY}

There was considerable discussion and disagreement among members of the senior management team as to whether any single subject should host more than one key skill. It was decided not. Subjects chosen for key skills delivery would host either Communication or Application of Number, but not both. Despite the willingness of some subject teachers to host two key skills, the Heads of Faculty refused to take responsibility for non-attainment of targets in the event of teaching time for subjects being reduced as a result of hosting both Communication and Application of Number.

Meetings of the senior management team were held regularly to decide which subjects from Groups I to IV would be used to deliver Communication and Application of Number. The meetings were poorly managed and repetitious, tackling issues afresh with members introducing anecdotes at will to support or dispute claims for inclusion. In the end, a key skills co-ordinator was appointed temporarily to the senior management team to resolve the issue of selecting host subjects for key skills delivery. She in turn delegated the Careers Guidance staff to survey (again) the students from Year 11 and to recommend at least one subject from each group to host each key skill. Table 3 shows the results.

A number of decisions had been taken by the senior management team prior to the selection of host subjects:

- It was decided to offer General Studies as an A level in Year 12 only and it was consequently deemed unsuitable for hosting any key skills delivery.

- Mathematics was not chosen for delivery of Application of Number. The Careers and Guidance staff advised that students associated mathematics with (at worst) failure and (at best) unpopularity, and that mathematics teachers were not necessarily the most suitable teachers of Application of Number.

- While there was a conscious attempt made to accommodate all desired subject combinations in the Year 12 groupings, there was an acceptance 
Table 3 Host Subjects

\begin{tabular}{lll}
\hline $\begin{array}{l}\text { Subjects used to deliver } \\
\text { Communication }\end{array}$ & $\begin{array}{l}\text { Subjects used to deliver } \\
\text { Application of Number }\end{array}$ & $\begin{array}{l}\text { Subjects not used for } \\
\text { key skills delivery }\end{array}$ \\
\hline English (Lit.) & Economics & Biology \\
English (Lang.) & Geography & Maths \\
French & Physics & PE \\
German & Chemistry & Art \& Design \\
Spanish & Technology & General Studies \\
History & & \\
Business Studies & &
\end{tabular}

Computer Studies used to deliver IT key skills: compulsory for all students at AS level.

among senior managers that some combinations would be impossible to offer and that others would, unfortunately, avoid key skills development either in part or completely.

- In the case of students doing more than one of the host subjects for Communication or Application of Number, it was accepted that there would be duplication of delivery. However, it was hoped that the key skills would be presented in such a way as to unobtrusively benefit the host subject in any case and being an integrated delivery system meant that the duplication did not 'cost' the school in terms of staffing. If students benefited from getting more than the minimum amount of key skills development at no additional cost to the school, so much the better.

- All A level students were expected to reach Level 3 in each of the key skills and there was no support facility for students who could not. The senior management team acknowledged this as a major source of concern for staff.

\section{ANALYSIS OF PROPOSED KEY SKILLS DELIVERY STRUCTURE}

When the proposed structure for hosting key skills was discussed by the senior management team, two major flaws were uncovered in the delivery structure: the influence of host subject popularity; and a gender imbalance in the sets of host subjects used to deliver Communication and Application of Number.

Generally, members of the senior management team were of the opinion that developing skills in Communication was going to be less problematic than developing skills in Application of Number. Recent research (West and Dee et al., 2000) has reported that this is a commonly held opinion, although 
whether Communication is actually less problematic to deliver or just perceived as such remains unclear. The senior management team felt that the subjects that had been selected to host Communication and Application of Number were going to accentuate this problem, as a comparison between Figure 1 and Table 3 reveals. The subjects chosen to deliver Communication were generally more popular and had a lower requirement for HE entry than those subjects chosen for delivery of Application of Number. Consequently, Application of Number would have started with the inherent disadvantages of unpopularity and obligation.

Of greater concern was the gender imbalance inherent in the selection of host subjects. Table 4 shows the male/female divide for each subject offered at A level in the school and Table 5 shows the male/female divide for each subject used to host key skills delivery.

While the gender balance in each subject group was fairly even, there was a striking imbalance between the sets of subjects used to host Communication and those used to host Application of Number. It became apparent to the senior management team that female students, by virtue of their probable subject choice at A level, stood a greater chance of achieving Communication proficiency than Number proficiency, and that the converse was true for male students. Furthermore, such a key skills delivery model merely sustained the

Table 4 Gender Balance for A level Subjects

\begin{tabular}{llll}
\hline Group I & $\%$ male/female & Group III & $\%$ male/female \\
\hline Economics & $64 / 36$ & Biology & $39 / 61$ \\
Biology & $39 / 61$ & English (Lit.) & $30 / 70$ \\
Spanish & $29 / 71$ & French & $29 / 71$ \\
Maths & $62 / 38$ & Physics & $76 / 24$ \\
General Studies & $49 / 51$ & Business Studies & $47 / 53$ \\
& & & \\
Average & $49 / 51$ & Average & $44 / 56$ \\
\hline Group II & & Group IV & \\
\hline Maths & $62 / 38$ & Geography & $55 / 45$ \\
Geography & $55 / 45$ & Art & $38 / 62$ \\
English (Lang.) & $37 / 63$ & Technology & $77 / 23$ \\
History & $44 / 56$ & Chemistry & $54 / 46$ \\
German & $31 / 69$ & English (Lit.) & $30 / 70$ \\
PE & $64 / 36$ & & \\
Average & $49 / 51$ & Average & $51 / 49$ \\
\hline
\end{tabular}

Source: DfEE statistics 1997/8. 
Table 5 Gender Balance for Host Subjects

\begin{tabular}{llll}
\hline $\begin{array}{l}\text { Subjects used to deliver } \\
\text { Communication }\end{array}$ & $\begin{array}{l}\text { \% male/ } \\
\text { female }\end{array}$ & $\begin{array}{l}\text { Subjects used to deliver } \\
\text { Application of Number }\end{array}$ & $\begin{array}{l}\text { \% male/ } \\
\text { female }\end{array}$ \\
\hline English (Lit.) & $30 / 70$ & Economics & $64 / 36$ \\
English (Lang.) & $37 / 63$ & Geography & $55 / 45$ \\
French & $29 / 71$ & Physics & $76 / 24$ \\
German & $31 / 69$ & Chemistry & $54 / 46$ \\
Spanish & $29 / 71$ & Technology & $77 / 23$ \\
History & $44 / 56$ & & \\
Business Studies & $47 / 53$ & & $65 / 35$ \\
Average & $35 / 65$ & Average & \\
\hline
\end{tabular}

Source: DfEE statistics 1997/8.

existing divide between girls and languages on the one hand, and boys and hard sciences on the other.

\section{REDESIGN: THE PROCESS OF STAFF INVOLVEMENT}

When the Head and senior management team became aware of the inherent imbalances in their chosen key skills delivery structure, they decided to redesign it entirely. The key skills co-ordinator, already co-opted onto the senior management team, was charged with organizing staff input into the process. Assurances were sought and given that any reasonable suggestions from staff for an improved delivery model would at least be considered.

The key skills co-ordinator agreed the structure for staff involvement depicted in Figure 2. Staff were briefed and encouraged to volunteer for one or more of the small teams (called 'issue teams') set up to examine various issues, such as accreditation, delivery models, resources, standards and public relations.

Typically, there were five issue teams in operation at any given time, but sometimes as few as one. They were all given a time-frame within which to work and specific guidelines as to the sort of outcome expected. They were obliged to keep minutes and notes from meetings and the procedure was subsequently reported as being 'surprisingly formal'. Issue teams were chaired by members of the key skills team, which in turn was chaired by the key skills coordinator. Thus a link was established between the teaching staff and the senior management team, via the key skills co-ordinator and her team. Issue teams were disbanded when the outcome was achieved or when their consideration time was up. Some teams and some issues were extended; others were not. The teams ranged in size from three to ten, but averaged four members. 


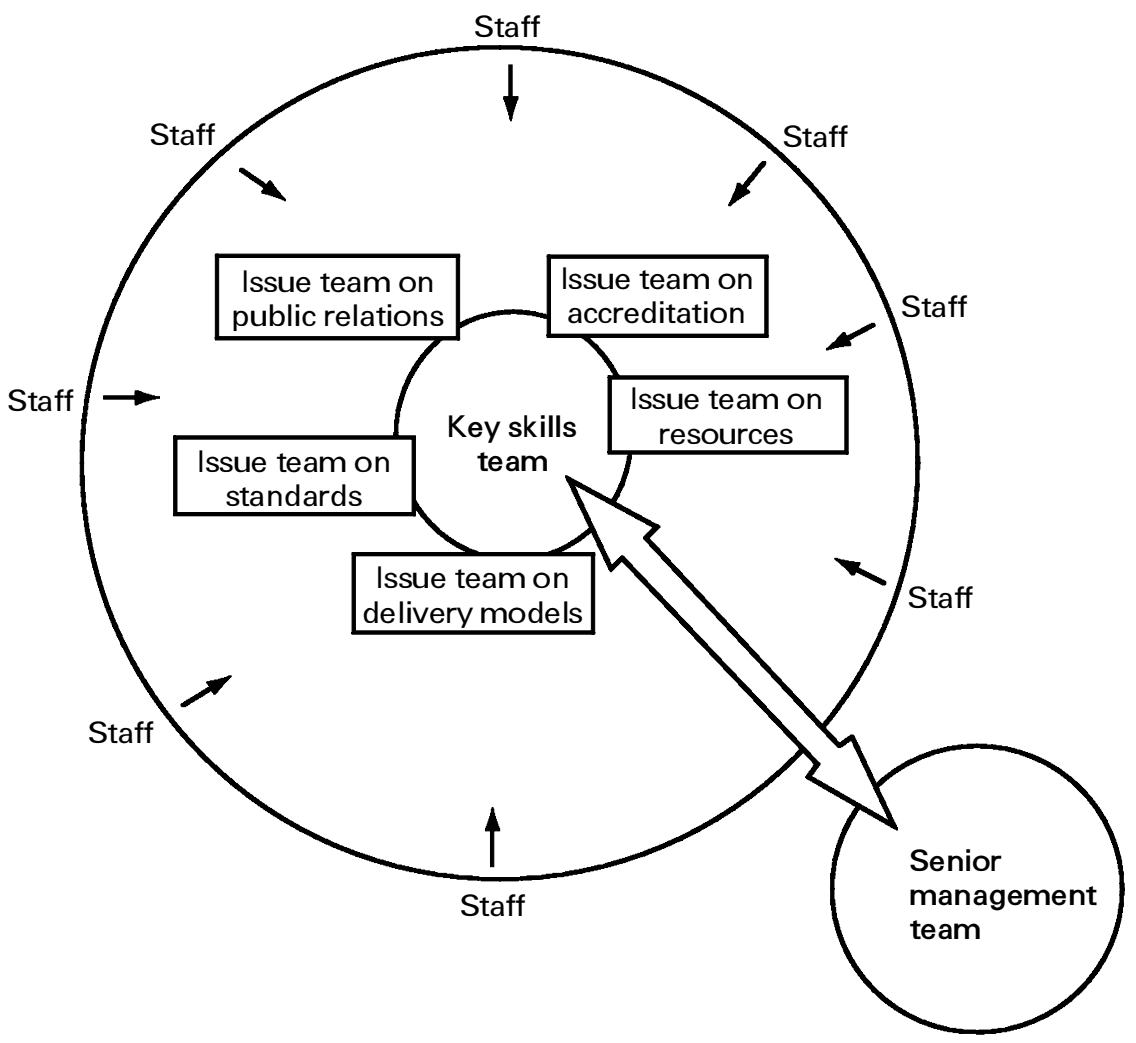

Figure 2 Staff involvement in curriculum design

The decision to centre teams of staff around issues, rather than by subject or faculty, was a deliberate one. The key skills co-ordinator felt (and staff on the teams subsequently agreed) that it was wiser not to group staff from the same faculty together, as it would be more likely to encourage partisanship, inhibit creative thinking and concentrate attention on the ever-vexed question of departmental budget. The issue teams comprised members from various faculties within the school and that way, it was thought, would have a wider, whole-school, view of things.

Membership of the issue teams was by open invitation to the staff, although some coercion by Heads of Faculty was not unknown, especially when it came to membership of the team discussing resources and finance! While the notion of teams built around issues (rather than around the existing departmental structures) worked well, there were problems:

- The five Heads of Faculty in the school were line managed by the Curriculum Deputy who was separately charged with examining the relative 
facility of A level subjects to accommodate key skills teaching and assessment. This process went on in parallel with that of the issue teams and the key skills co-ordinator felt that she was deliberately not kept up to date with discussion in this forum.

- The Deputy Head (Pastoral) was adamant that the tutorial system would not be used for monitoring 'an individual curriculum issue like key skills'. Consequently, there was little input from the Heads of Year into the 'monitoring and tracking' issue team, which was eventually disbanded without having reached any conclusions.

- There was dissatisfaction among some teachers that the 'big' issues were really confined to the senior management team, but it cannot be said that this feeling was widespread.

Despite these problems, the use of issue teams was judged a success by the Head and the senior management team, who felt that the key skills co-ordinator had done exceptionally well to democratize the introduction of key skills into the school. Subsequently, the staff recommendations for key skills delivery that arose from this consultative process were adopted without any significant amendment.

\section{REDESIGN: THE OUTCOME}

The design of the new delivery model was based on the deliberations of the issue teams, which recommended the following three underpinning principles:

- Key skills should be integrated as much as possible into the mainstream of academic study to ensure that the key skills qualification was perceived by students as part and parcel of their learning experience.

- In the interim, at least, only some subjects should be used to host Communication or Application of Number, to ensure that only staff who felt confident and competent to teach key skills were involved.

- Students should be expected to aspire to Level 3 in all three key skills, with reasonable support provided for those students having difficulty.

Based on these three underpinning principles, and with the agreement of all teaching staff involved, the following recommendations were made and subsequently adopted by the senior management team. They formed the basis for the new delivery structure.

- Art and Design was to be chosen as a host subject for Application of Number.

- Business Studies was to be chosen as a host subject for Application of Number, rather than Communication. 
- General Studies was to be made compulsory for all students in Year 12 (AS) and was to be made available over two years, rather than one, as a full A level.

- General Studies was to provide support for both Communication and Application of Number to students whose subject choices resulted in a shortfall in their key skills development.

- Each student was to be provided with a key skills manifesto which set out what the student was expected to achieve in order to reach Level 3 in both key skills by the end of Year 12. Students were to have their key skills units mapped against their subject choices and the deficit made up by General Studies and the General Studies teachers, who would be kept informed of student progress by the key skills monitoring team.

- External assessment was to be undertaken in Year 12, with portfolio development in Year 13.

- Since the success of the system depended on continuous co-ordination between the key skills team and the supporting General Studies staff, teachers involved in either co-ordination or General Studies were to be allowed one hour per week time-in-lieu for their extra monitoring responsibilities.

- Information Technology was to remain delivered in a discrete manner, with its own support structure, but working to the same time-frame and levels as the other two key skills.

Figure 3 attempts to capture the new structure schematically.

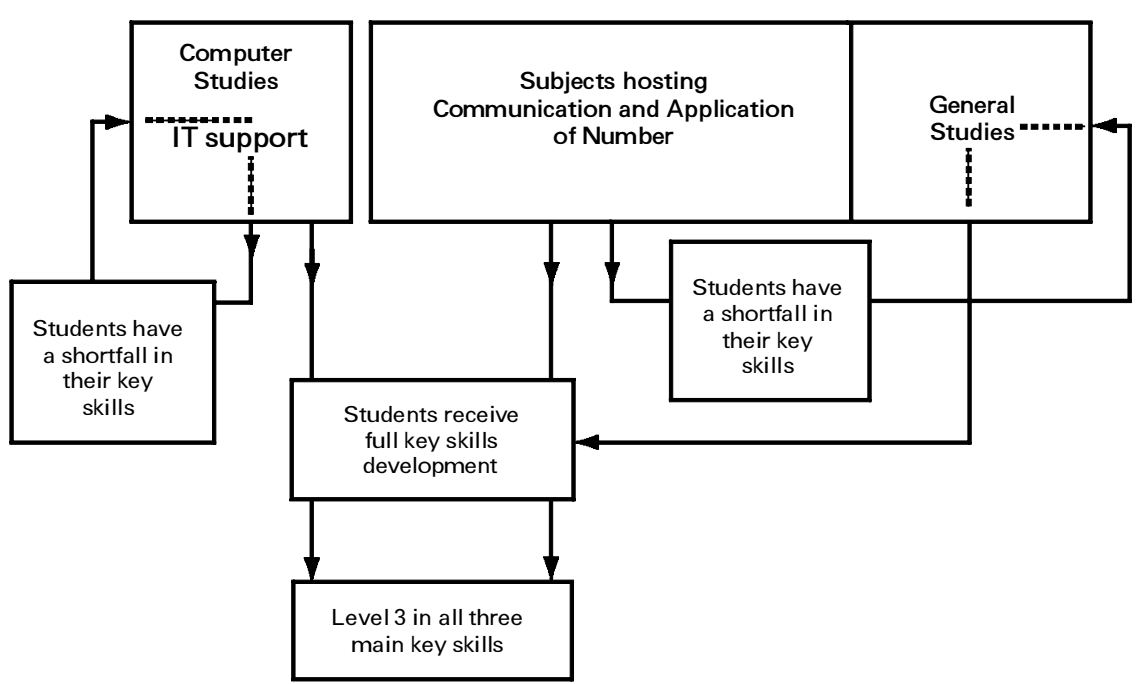

Figure 3 The revised structure for key skills delivery 


\section{CONCLUSIONS}

Every school and college has its strengths and weaknesses, so it is supposed that institutions learn from each other by sharing both successful and unsuccessful practice. However, sharing experience within an institution can be part of a learning process too and can lead to a general improvement in teaching, learning, management and professional development. With that in mind, the following observations on their experiences were made by those involved in this study:

- The senior management team felt, in retrospect, that they were hurried into a premature decision concerning the structures for delivering Curriculum 2000 and key skills, caused in part, at least, by a lack of time set aside for planning at senior management level.

- The senior management team felt that the need for planning time was particularly acute in their traditional school where, as a result of the academic demands made on it, there was greater inertia, a slower response time to problems and little experience of managing change.

- The tradition of top-down management in the school was felt by the Head to be no longer appropriate, given that there was as much experience of innovation in the staffroom as in the senior management team, which the school could ill afford to ignore.

- The top-down management structure within the school was also felt by staff to encourage inertia and slow down the process of feedback and response.

- Those staff involved in issue teams (approximately three-quarters of all full-time staff) felt that their sense of ownership of the new curriculum was important to its success and that their involvement at the design stage was a source of much encouragement.

- The senior management team decided that major structural changes should in future be given a 'trial' period, during which proposals could be examined by staff with a view to uncovering inherent flaws or problems specific to individual teachers or departments. This would be done without prejudice to the senior management team's right to lead the school or to be agents for change within it.

- Staff felt that the single most important ingredient in the success of the redesign process, and staff involvement in it, was the guarantee from the senior management team that they would consider all reasonable recommendations. In particular, the fact that staff recommendations were eventually adopted en bloc had initiated a new culture of trust and mutual respect between staff and management. 


\section{FINAL REMARKS}

Curriculum change always represents a significant challenge to teachers and managers. In the case of key skills, it requires a change in teaching style that cannot be mandated from the top, as this case-study illustrates. Senior management does have an important role to play, of course, but that role is in focusing and pulling together, rather than in prescribing. Managers need to allow individual teachers a minimum threshold of flexibility so that they can properly employ their creative strengths during implementation, while at the same time ensuring that staff are working to common goals.

This study suggests that the way in which individuals are involved in the planning process has a significant impact on outcome and that a more participative approach leads to greater voluntary involvement in the process of effecting change. The evident sense of co-ownership appears to encourage critical reflection while lessening the influence of those who choose not to participate.

Critical reflection and evaluation are activities that should bring benefits at every stage. Too often, the inclination is to quality control the output rather than quality assure the process, and evaluation takes place only when it is too late. This study suggests that subjecting decisions to critical scrutiny while the process is under way not only produces a more focused and better thought-out strategy, but also leaves staff better equipped to handle change in the future.

\section{REFERENCES}

DfEE (1998) Education and Training Statistics for the UK. London: The Stationery Office.

West, M. and Dee, L. (2000) The Key Skills Support Programme: Implementation Needs in Schools and Colleges. London: Further Education Development Agency. 